\title{
Organizational intelligence dismounting barriers prioritization: A real-world case study
}

\author{
Ali Shahabi ${ }^{a^{*}}$, Ali Faez ${ }^{\mathrm{b}}$ and Damoon Fazli ${ }^{\mathrm{c}}$
}

\begin{tabular}{l}
${ }^{a}$ Member of Young Researchers Club \\
${ }^{b}$ Department of Management and Accour \\
${ }^{c}$ EMBA(STRATEJIC) student, Islamic \\
\hline A R T I C L E I N F O \\
\hline Article history: \\
Received June 28, 2012 \\
Received in Revised form \\
August, 26, 2012 \\
Accepted 29 August 2012 \\
Available online \\
8 September 2012 \\
\hline Keywords: \\
Organizational intelligence \\
Organizational intelligence \\
dismounting barriers \\
Knowledge management \\
\end{tabular}

\author{
Islamic Azad University of Semnan, Iran \\ ing, Islamic Azad University of Semnan, Semnan Branch, Semnan, Iran
}

\begin{abstract}
A B S T R A C T
Organizational intelligence plays an important role developing business units and organizations. Understating the barriers surrounding an organization helps us take possible actions to remove any issues. In this paper, we present an empirical investigation to find barriers in university located in Province of Semnan, Iran. The proposed study of this paper first detects important barriers and then prioritize them using analytical hierarchy process. Based on the results of this paper, structural barriers are considered as the most important issue follows by legal barriers, cultural and executive barriers. The results of our survey indicate that lack of organizational knowledge management relation with daily activities, project complexity, lack of the knowledge exchanging and sharing in the organization, lack of suitable business context and absence of a documented program for the organizational intelligence dismounting are among the most important barriers according to our AHP implementation results.
\end{abstract}

\section{Introduction}

In today's competitive and complex world, the organizations need to incorporate modern knowledge to survive. The social knowledge is a way for working with different knowledge based skills, which exist among the individuals at the various relational structures and credit and deep dialogue and creative contact (Barben, 2005). This is the social capital, which supports the knowledge streams in the society (George \& Gelauff, 2003). The university society generally consists of masters with wisdom and science seekers who enjoy some degrees of knowledge and they are interested in growth. Preparing a suitable infrastructure and managing the desirable remedies creates the opportunities among most of these individuals to acquire the necessary knowledge or to transfer the knowledge to others and to follow more sharing the knowledge. Education is the development axis and, on the other hand a part of all of the development designs (Golshan, 2004). 
Individuals who seek for employing and serving in the society and look for enjoying the social life advantage, are forced to spend many years of their own lives at the formal educational centers. Therefore, existence of a knowledge-based system can worthy help to enhance the society. The organizational intelligence is a fairly new issue, where many individuals are not familiar with it, yet, for example, Lefter et al. (2008) demonstrated that only 13\% of Romanian big factories' workers were familiar with the concept of organizational intelligence (Lefter, et al., 2008). Of course, the concepts like emotional intelligence and multi-folded intelligence, which have been presented by Goleman and Gardener, respectively, have significantly contributed to development of the organizational and individual intelligence concepts (Salasel, et al., 2009).

However, this topic needs more examinations and investigations. Tseng and kove (2010) attempted to examine the sociological and social capital factors influencing on the knowledge sharing and showed that these factors could enhance the understanding in knowledge management process (Tseng \& Kuo, 2010). Organizational intelligence theory seeks to determine the organizations' abilities and weaknesses, measuring their intelligibility state and based on the attained results, to present the remedies necessary for organizational intelligence improvement and at the end for the organization performance improvement (Jafari \& Faghihi, 2009).

Schwaninger (2001) believed that the organizations beside of being pure, fast and powerful need to be more intelligence and they can achieve to this importance issue, by adapting, learning and selfcharging. Dismounting the organizational intelligence normally depends on dismounting the knowledge management and it is also considered as social capital (Hey et al., 2009). Therefore, with respect to the relative importance and the organizational intelligence station in the organizations and particularly in the teaching contexts, in this article, organizational intelligence dismounting barriers are prioritized by analytical hierarchy process (AHP) method.

\section{Theoretical research foundations}

In this section, knowledge management and some of the most important barriers of dismounting it in the organizations are presented while reviewing on the literature related to the organizational intelligence.

\subsection{Organizational Intelligence}

Organizational intelligence was for the first time proposed in 1990s, and its root goes back to organizational learning and knowledge management theories. However, speaking about organizational intelligence was started in1992 for the first time (Jafari \& Faghihi, 2009). Organizational intelligence is the organization ability to solve organizational problems (Matsuda, 1992). There are literally different studies associated with organization intelligence. Azma et al. (2012) investigated the application of information technology and its relations with organizational intelligence in the employees of universities in Golestan province. The study designed and distributed questionnaire among some university employees in Golestan province in Iran. The results showed there was a significant relationship in applying information technology with tendency to change, applying knowledge and common perspective.

Saeidipour et al. (2012) studied the impact of "emotional intelligence" on "organizational learning" among employees who worked for Jihad Agriculture organization of Isfahan and their results in a significant level of $99 \%$ showed that emotional intelligence had a significant effect on organizational learning. Organizational intelligence is also associated with emotional intelligence and there are different studies associated with emotional intelligence. Feizi and Abedini (2010), for instance investigated the relationship between emotional intelligence and social capital by investigating on a real-world case study. Jahanian (2010) in other essay studied the relationship between emotional 
intelligence and conflict management among some managers in other real-world applications. Organizational intelligence is an ability that causes the organization mind power to move, and placed it in direction of the organization objectives (Albrecht, 2003). Organizational intelligence is a mixture of the abilities such as flexibility, changeability and new-building (Erçetin \& Demirbulak, 2002). Liebowitz (1999) defined the organizational intelligence as all of the intelligibilities set of an organization used to create a common view, total direction, controlling and reviewing process (Liebowitz, 1999). Organizational intelligence process includes below 5 stages: (Unland, 1994).

$>$ Organizational memory: ability of collecting and maintaining the information needed by the organization.

> Organizational knowledge: ability of understanding and analyzing this information.

$>$ Organizational learning: ability of applying the attained knowledge.

$>$ Organizational communication: exchanging the information and knowledge among the organization members.

$>$ Organizational conclusion: acquiring the success and overcoming on the problems.

According to Albrecht (2002, 2003), organizational intelligence has been dimensions as follows,

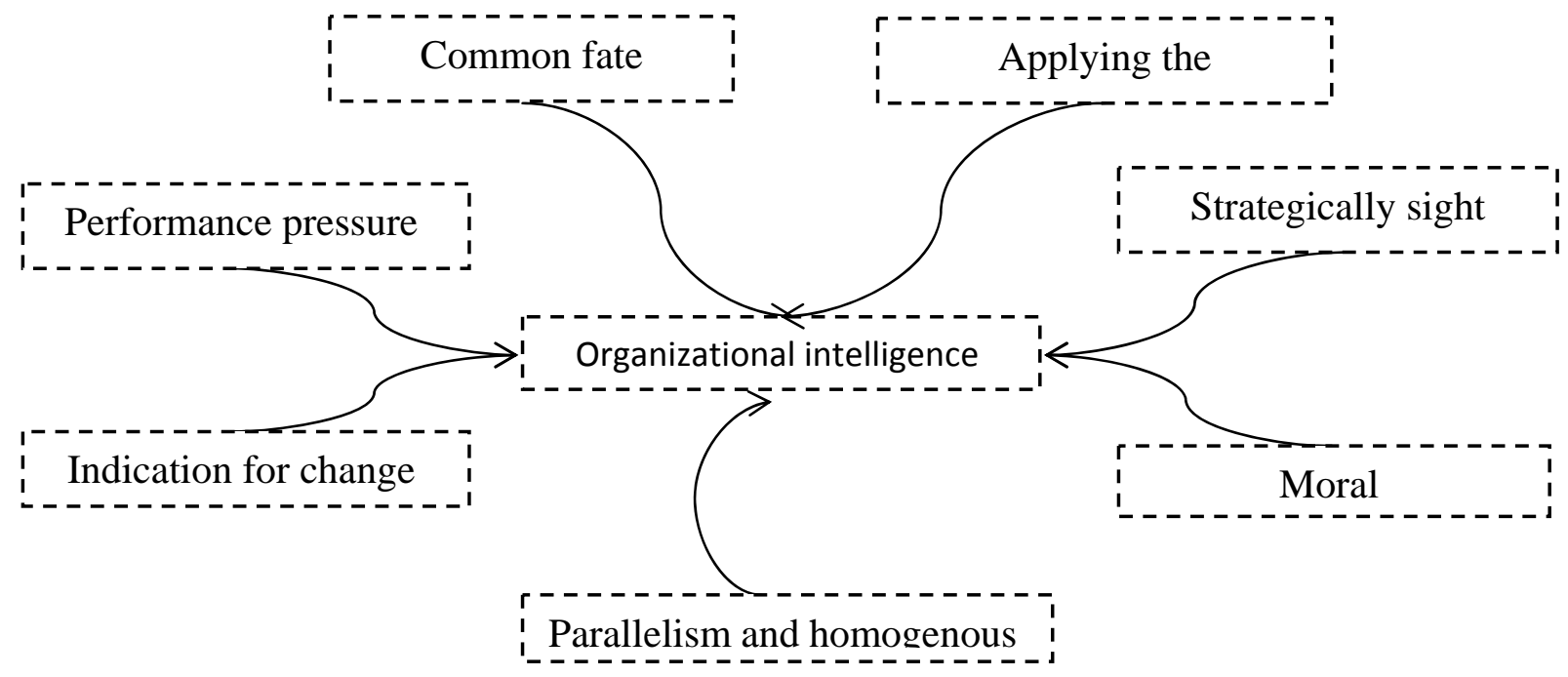

Fig. 1. Organizational intelligence dimensions (Albrecht, 2002)

As observed from Fig. 1, organizational intelligence has different dimensions. For accessing to the ideal organizational intelligence, existence of all of the above dimensions is necessary. Organizational intelligence effects on the individuals' social and personal life (Brackett \& Mayer, 2003) and leads to better behaviors in the family and work context and improves the group work and function (Goleman, 1995). So, the organizational intelligence increases the whole organization and individual's flexibility along the changes, enhancing the individual's powerfulness in various fields and makes the organization more powerful to access to its objectives.

\subsection{Knowledge Management}

At the first time, in 1986, Wigg (2007), in his book mentioned the knowledge management. However, before that, others also had implicitly given glad tidings about appearance of this phenomenon. In one division, one can divide the knowledge into two aspects of tacit knowledge and explicit knowledge (Wiig, 1997). Also, in the knowledge sharing process, four kinds of knowledge have play important role, which include professional knowledge, coordinating knowledge, object-based knowledge and 
technical knowledge (Holdt, 2007). Knowledge management refers to a set of processes maintained and used and its purpose is to exploit the mined assets to increase the profitability, creating the new values and enhancing the compatibility. By globalization and internet effect, many organizations have geographically been dispersed and are built as figurative teams. Also, by increasing the count of the documents and evidences that are existent in web-based context, many problems at the knowledge management field have created and they have shown themselves at the fields like searching the information, extracting the information, maintaining and accessing the information (Hammer \& Stanton, 1994). Advantages of applying the knowledge management included increasing the organizational learning, mind capitals advanced management, increasing the functions effectiveness and efficiency and continued and permanent improvement (Demarest, 1997). We can conclude that the organizational intelligence dismounting in the organizations specially in a teaching context, is to store dependent on the knowledge management of the individual group and management levels.

\subsection{Identifying the barriers and challenges of dismounting the organizational intelligence}

Organizational intelligence by itself is a process or an achievement from a process (Matsuda, 1992) and the proposed study of this paper attempts to detect its barriers. Some of the organizational intelligence dismounting barriers identified based on the previous studies and free interview with the elites are as below:

$>$ Absence of the sufficient information at the organizational intelligence dismounting field,

$>$ Lack of the managers support,

$>$ Lack of sufficient ability and willing of the managers and works at dismounting it,

$>$ Weakness at social capital,

$>$ Weakness at knowledge management,

$>$ Complexity of the process,

$>$ The country macro-policies deficiency,

$>$ Rules deficiency at re-structuring,

$>$ Lack of public information about the organizational intelligence advantages,

$>$ Numerous decision making centers.

There are also other various vases, which generally influence on the modern process dismounting. Ali khan et al. (2010) presented the cases like lack of participating the workers at the decision making process, the workers resistance against the changes and lack of accessibility to the correct information as the trade intelligence barriers (Ali Khan et al., 2010).

\section{Research Methodology}

In this research, measuring method has been used to assess the organizational intelligence dismounting barriers. For collecting the needed data, two kinds of questionnaires consists of 18 questions on organizational intelligence dismounting barriers were used. The questionnaires were completed by 31 Semnan Azad university professors who had studied at the organizational intelligence field and had arbitrarily been selected based on the classified random sampling. The second questionnaire, dedicated to prioritizing the barriers, was completed by 10 elites (experienced professors) using AHP method. Cronbakh alpha was calculated as 0.801 , which is well above the minimum acceptable level.

\subsection{Research Hypothesizes}

1- There is a direct link between structural barriers and organizational intelligence dismounting.

2- There is a direct link between legal barriers and organizational intelligence dismounting. 
3- There is a direct between executive barriers and organizational intelligence dismounting.

4- There is a direct link between cultural barriers and organizational intelligence dismounting.

\subsection{AHP Decision Tree}

Fig. 2 shows the organizational intelligence dismounting decision tree based on AHP.

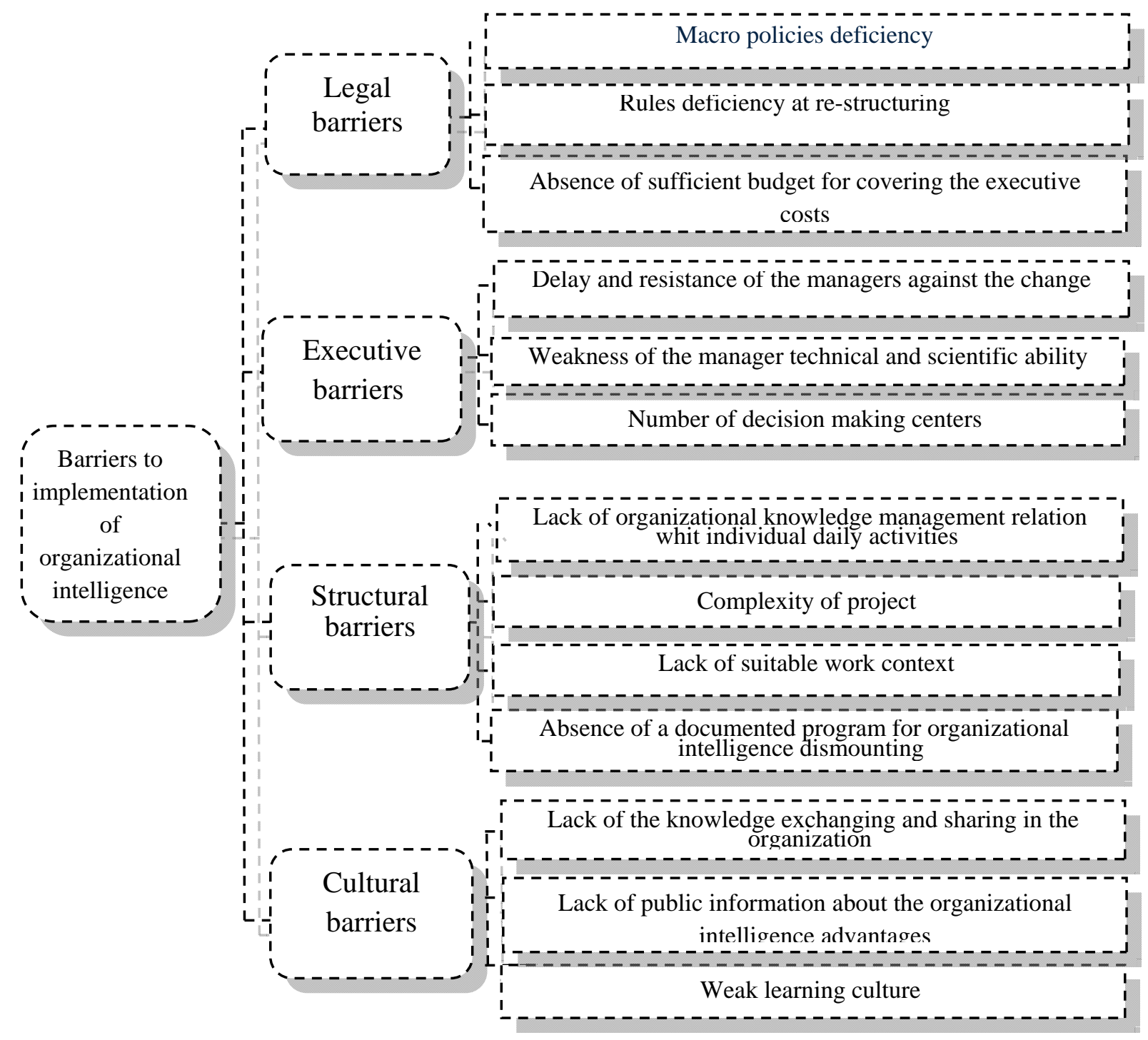

\subsection{Research Data Analysis}

Fig. 2. AHP decision tree

Data analysis is performed in two parts of factors finalization and prioritization.

\subsubsection{First questionnaire data analysis (factors finalization)}

As previously pointed out, for finalizing the organizational intelligence dismounting barriers, a questionnaire was designed that in this part, the attained data analysis is conducted by correlation coefficient method. 


\section{First Hypothesis}

Correlation test results associated with the first hypothesis are shown in Table 1 . As indicated by the results, correlation coefficient is equal to 0.87 with the significant level of 0.000 , which is smaller than 0.05. Therefore, at the significant level $0.05, \mathrm{H}_{0}$ hypothesis is rejected and $\mathrm{H}_{1}$ hypothesis is accepted, that is, there is a significant correlation between structural barriers and organizational intelligent dismounting.

\section{Table 1}

First hypothesis (correlation test results)

\begin{tabular}{llll}
\hline & & Structural barriers & Organizational intelligence dismounting \\
\hline \multirow{2}{*}{ Structural barriers } & Pearson correlation coefficient & 1 & 0.87 \\
& Test significant level & & 0.000 \\
& Sample mass & 31 & 31 \\
\hline Organizational & Pearson correlation coefficient & 0.87 & 1 \\
intelligence & Test significant level & 0.000 & 31 \\
dismounting & Sample mass & 31 & 31 \\
\hline
\end{tabular}

\section{Second Hypothesis}

Correlation test results relating to the second hypothesis have been shown in Table 2.

Table 2

Second hypothesis (correlation test results)

Correlatio

\begin{tabular}{llll}
\hline \multirow{2}{*}{ Legal barriers } & & Legal barriers & $\begin{array}{l}\text { Organizational } \\
\text { dismounting }\end{array}$ \\
& Pearson correlation coefficient & 1 & 0.76 \\
& Test significant level & & 0.000 \\
\hline \multirow{2}{*}{$\begin{array}{l}\text { Organizational intelligence } \\
\text { dismounting }\end{array}$} & Sample mass & 31 & 31 \\
\cline { 2 - 4 } & Pearson correlation coefficient & 0.76 & 1 \\
\cline { 2 - 4 } & Test significant level & 0.000 & 31 \\
\cline { 2 - 4 } & Sample mass & 31 & \\
\hline
\end{tabular}

As indicated by the results, correlation coefficient is equal to 0.76 and the significant level is equal to 0.000 , which is smaller than 0.05 . Therefore, at the significant level $0.05, \mathrm{H}_{0}$ hypothesis is rejected and $\mathrm{H}_{1}$ hypothesis is accepted, that is, there is a significant correlation between legal barriers and organizational intelligent dismounting.

\section{Third Hypothesis}

Correlation test results relating to the third hypothesis have been shown in Table 3.

Table 3

Third hypothesis (correlation test results)

\begin{tabular}{|c|c|c|c|}
\hline \multicolumn{4}{|l|}{ Correlation } \\
\hline & & $\begin{array}{l}\text { Executive } \\
\text { barriers }\end{array}$ & $\begin{array}{c}\text { Organizational intelligence } \\
\text { dismounting }\end{array}$ \\
\hline \multirow{3}{*}{ Executive barriers } & Pearson correlation coefficient & 1 & 0.68 \\
\hline & Test significant level & & 0.008 \\
\hline & Sample mass & 31 & 31 \\
\hline \multirow{3}{*}{$\begin{array}{l}\text { Organizational intelligence } \\
\text { dismounting }\end{array}$} & Pearson correlation coefficient & 0.68 & 1 \\
\hline & Test significant level & 0.008 & \\
\hline & Sample mass & 31 & 31 \\
\hline
\end{tabular}


As indicated by the results, correlation coefficient is equal to 0.68 and the attained significant level is equal to 0.008 , which is smaller than 0.05. Therefore, at the significant level $0.05, \mathrm{H}_{0}$ hypothesis is rejected and $\mathrm{H}_{1}$ hypothesis is accepted, that is, there is a significant correlation between executive barriers and organizational intelligent dismounting.

\section{Fourth Hypothesis}

Correlation test results relating to the third hypothesis are shown in Table 4.

\section{Table 4}

Fourth hypothesis (correlation test results)

\begin{tabular}{|c|c|c|c|}
\hline \multicolumn{4}{|l|}{ Correlation } \\
\hline & & Cultural barriers & Organizational intelligence dismounting \\
\hline \multirow{3}{*}{ Cultural barriers } & $\begin{array}{l}\text { Pearson correlation } \\
\text { coefficient }\end{array}$ & 1 & 0.71 \\
\hline & Test significant level & & 0.014 \\
\hline & Sample mass & 31 & 31 \\
\hline \multirow{3}{*}{$\begin{array}{l}\text { Organizational intelligence } \\
\text { dismounting }\end{array}$} & $\begin{array}{l}\text { Pearson correlation } \\
\text { coefficient }\end{array}$ & 0.71 & 1 \\
\hline & Test significant level & 0.014 & \\
\hline & Sample mass & 31 & 31 \\
\hline
\end{tabular}

As indicated by the results, correlation coefficient is equal to 0.71 and the attained significant level is equal to 0.014 , which is smaller than 0.05 . Therefore, at the significant level $0.05, \mathrm{H}_{0}$ hypothesis is rejected and $\mathrm{H}_{1}$ hypothesis is accepted, that is, there is a significant correlation between cultural barriers and organizational intelligent dismounting. Therefore, we can certainly state that the mentioned 4 factors, have correctly been selected as the organizational intelligence dismounting barriers. Therefore, prioritizing these factors is performed at the next section, emphasizing on effectiveness of these factors at the organizational intelligence dismounting.

\subsubsection{Second Questionnaire Data Analysis (barriers prioritization)}

Table 5 shows the compound doubled comparisons matrix of the organizational intelligence dismounting barriers, that was product of compounding 10 doubled comparisons matrix, which has been completed by the elites. Table numbers indicate the priority of each factor compared with other factor.

\section{Table 5}

Normalized matrix of the compound doubled comparisons of the principle barriers with weights

\begin{tabular}{llllllll}
\hline & $\begin{array}{l}\text { Structural } \\
\text { barriers }\end{array}$ & $\begin{array}{l}\text { Legal } \\
\text { barriers }\end{array}$ & $\begin{array}{l}\text { Cultural } \\
\text { barriers }\end{array}$ & $\begin{array}{l}\text { Executive } \\
\text { barriers }\end{array}$ & Weights & WSV & CV \\
\hline Structural barriers & 0.486 & 0.560 & 0.44 & 0.376 & 0.472 & 2.09 & 4.39 \\
Legal barriers & 0.189 & 0.235 & 0.31 & 0.27 & 0.30 & 1.253 & 4.41 \\
Cultural barriers & 0.173 & 0.1 & 0.15 & 0.17 & 0.128 & 0.60 & 4.39 \\
Executive barriers & 0.150 & 0.083 & 0.098 & 0.91 & 0.09 & 0.41 & 3.85 \\
\hline \multicolumn{7}{c}{$C I=0.071$} & \multicolumn{5}{c}{$C R=0.079$} \\
\hline
\end{tabular}

The results of Table 6 show that from the elite professor's point of view, the structural barriers with the weight 0.472 are the most important organization intelligence dismounting barriers in a teaching context. Also, with respect to this fact that CR is smaller than 0.1 , the table has consistency. 


\section{Table 6}

Principle barriers final ranking based on AHP

\begin{tabular}{llllll}
\hline Rank & 1 & 2 & 3 & 4 & Total weights \\
\hline Barriers & Structural barriers & Legal barriers & Cultural barriers & Executive barriers & \\
\hline Weight & 0.472 & 0.30 & 0.128 & 0.09 & 1 \\
\hline
\end{tabular}

Table 6 shows the organizational intelligence dismounting barriers ranking with the corresponded weights. According to the results of Table 6, it is observed that the indexes associated with structural factors, are more important in elite`s point of view. From the elite`s view, lack of the organizational knowledge management relationship with daily activities was the most important organizational intelligence dismounting barriers and it approves the vital rule of the knowledge management in the organization. Again, other indexes with their relative rankings and final weights have been presented in Table 7.

\section{Table 7}

Principle barriers sub-branches ranking

\begin{tabular}{lll}
\hline Rank & Barrier & Weight \\
\hline 1 & Lack of organizational knowledge management relation with daily activities & 0.199 \\
2 & Project complexity & 0.167 \\
3 & Lack of the knowledge exchanging and sharing in the organization & 0.122 \\
4 & Lack of suitable business context & 0.117 \\
5 & Absence of a documented program for the organizational intelligence dismounting & 0.09 \\
6 & Macro policies deficiency & 0.071 \\
7 & Rules deficiency at re-structuring & 0.06 \\
8 & Weak learning culture & 0.057 \\
9 & Lack of public information about organizational intelligence advantages & 0.043 \\
10 & Weakness of the managers technical and scientific ability & 0.038 \\
11 & Absence of the sufficient budget for covering the executive costs & 0.025 \\
12 & Delay and resistance of the managers against charge & 0.0085 \\
13 & Numerous decision making centers & 0.0069 \\
\hline & Total weights & 1 \\
\hline
\end{tabular}

\section{Conclusion and Suggestions}

In this paper, we have presented an empirical investigation to find out the importation barriers in organizational intelligence. Based on the results of this paper, structural barriers are considered as the most important issue follows by legal barriers, cultural and executive barriers. In fact, lack of organizational knowledge management relation with daily activities, project complexity, lack of the knowledge exchanging and sharing in the organization, lack of suitable business context and absence of a documented program for the organizational intelligence dismounting are among the most important barriers according to our AHP implementation results. Based on the results of this survey we can provide the following suggestions for possible actions against barriers.

\section{Structural barriers removing suggestions}

Documenting a good program along with the organizational intelligence dismounting

$>$ Simplifying the process and process analysis along facilitating at the organizational intelligence dismounting process

$>$ More attending to the knowledge management and social capital

$>$ Designing and executing some plans for supporting the continued learning and job developing of all the workers 
Applying the correct methods of storing and recovering the information for increasing the organizational learning

Applying the methods and technologies of the modern information at the organization

$>$ Submitting the authority and defining the duties for creating the correct understanding of the functions and responsibilities

\section{Legal barriers removing suggestions}

$>$ Forming the macro management process rules on the organizational intelligence issue

$>$ Removing the constraint rules and regulations

$>$ Removing the budget limitations

$>$ Preparing the organizational intelligence dismounting charter

\section{Cultural barriers removing suggestions}

$>$ Some remedies for increasing the workers participation at the decision making and knowledge exchange

$>$ Organizing the cultural propagandistic activates for creating the organizational intelligence perceptive usefulness feeling

$>$ Correcting the responsible belief and credit in the organizational intelligence

$>$ Founding the learning and researches culture

$>$ Promoting and supporting the working incentives and forming the participation core and constituting the inherent working groups

$>$ Applying some remedies for increasing the mentality and willing for change in the workers

\section{Executive barriers removing suggestions}

Increasing the managers technical and scientific ability

$>$ Using the successful organizations expedients, inner and outer

$>$ Preventing from the individual activities and single-working along the organizational intelligence dismounting

\section{Reference}

Azma, F., Mostafapour, M.A., \& Rezaei, H. (2012). The application of information technology and its relationship with organizational intelligence. Procedia Technology, 1, 94-97.

Albrecht, K. (2002). Organizational intelligence and Knowledgemanagement the executive perspective. Retrieved, 2006, From.http://www.karl Albrecht.com.

Albrecht, K. (2003). The power of minds at work: Organizational intelligence in action. New York: Amacom.

Ali Khan, A., Amin, N., \& Lambrou, N. (2010). Drivers and barriers to business intelligence adoption: A case of Pakistan. European and Mediterranean Conference on Information Systems.

Barben, J. (2005). Social knowledge, Why I believe knowledge is constructed, emergent, ephemeral and tied to a community, available at : http://denham. typepad.com.

Brackett, M.A., \& Mayer, J.D. (2003). Convergent, discriminant, and incremental validity of competing measures of emotional intelligence. Personal and Social Psychology, 29, 1147-1158.

Demarest, M. (1997). Understanding knowledge management. Journal of Long Range Planning, 30(3), 374-384.

Erçetin, S. S., \& Demirbulak, D. (2002). Action research organizational intelligence. Educational Research Quarterly, 26(1), 41-49. 
Feizi, T., \& Abedini, S. (2010). The relationship between emotional intelligence and social capital (case study). Journal of Economics and Business, 1(1), 43-57.

George, M.M., \& Gelauff (2003). social capital: an indispensable asset in the knowledge - based economy, Paper for the workshop Social Capital and Economic Development on the occasion of the 75th anniversary of the University of Tilburg, March 27,

Goleman, D. (1995). Organizational Intelligence. NEW YORK: Bantam books.

Golshan, F., \& Mohammad, R. (2004). Tehran education sociology, Nashre Ravan [persian]

Hammer, M., \& Stanton, S.A. (1994). Reengineering work: Don't automate obliterate. Harvard Business Review, 68(4), 104-112.

He, W., Qiao, O., \& Kee Wei, K. (2009). Social relationship and its role in knowledge management systems usage. Information \& Management, 46(3), 175-180.

Holdt, C. P. ( 2007). Knowledge sharing: Moving away from the obsession with best practices. Journal of Knowledge Management, 11(1), 36-47.

Jafari. P., \& Faghihi. A. R. (2009). Organizational intelligence corporates amount at the research and knowledge teaching programimng and research organization at teaching sciences, khorasgan unit islamic azad university textbook programimng, 23, 45-66[persian]

Jahanian, R. (2010). Study the relationship between emotional intelligence and conflict management in managers. Journal of Management, 8, 1-8.

Lefter,V., Prejmerean, M., \& Vasilache, S. (2008), The dimension of organizational intelligence in Romanian companies-a human capital perspective. Academy of economic studies, Bucharest.

Liebowitz, J. (1999). Building organizational intelligence knowledge management primer. CRC press. Boca Paton London New York Washington. D.C.

Matsuda, T. (1992). Organizational Intelligence: Its Significance as a Process and as a Product, Proceedings of the International Conference on Economics/Management and Information Technology, Tokyo, Japan, August 31- September 4.

Rice, C.L. (1999). A quantitative study of emotional intelligence and its impact on team performance. Unpublished master's thesis, Pepperdine University.

Salasel, M., Kamkar, M., \& Golparvar, M. (2009). Relation of the organizational intelligence and its corporates with the citizenship behaviour. Research and Knowledge Magazine in Applied Psychology, $11^{\text {th }}$ year, 40[persian].

Schwaninger, M. (2001). Intelligent organizations: an integrative framework. John Wiley.

Saeidipour, B., Akbari, P., \& Marati Fashi, M.A. (2012). Study the effect of emotional intelligence on organizational learning staff, Case study: Jihad Agriculture Organization of Isfahan. Management Science Letters, 2(7), 2501-2510

Tseng, F., \& Kuo, F. (2010). The way we share and learn: An exploratory study of the self-regulatory mechanisms in the professional online learning community. Computers in Human Behavior, 26, 1043-1053.

Unland, R. (1994). Organizational Intelligence and Negotiation Based DAI Systems - Theoretical Foundations and Experimental Results. Working Papers of the Institute of Business Informatics, University of Munster, Germany.

Wiig, K. (1997). Knowledge management: where did it come from and where will it go. Expert Systems With Application, 13(1), 1-14. 